\title{
Understanding Leadership: Biographic, Gender and Social Aspects
}

\author{
Evgeny Rudnev, Ph.D. \\ Institute of Continuing Education, \\ Moscow State City Pedagogical University
}

\section{Doi:10.5901/mjss.2013.v4n9p714}

\begin{abstract}
The concept of "leadership" has become widely used in the social sciences after K.Levin experiments (USA, 30th years). He proposed a model for the implementation of changes identified three leadership styles (authoritarian, democratic and anarchist) and proved their direct impact on the "cluster environment» (Lewin, 1951). From this period, the term leadership is firmly embedded in psychological science. In 1943, psychologist K.Craik, continuing the development of ideas about the relationship with the leader of the group, suggested that all events are translated into the internal model, and that people use these models to evaluate external events. This communication theory suggests that people perceive the world through the prism of their psychological perception, and not just the outside world as a whole, despite the fact that they can feel that.
\end{abstract}

In the face of uncertainty, a lack of resources - material and human, fast-cerned obsolescence of information, uncertainty and continuous change - crisis - comes to the fore head of the leadership competencies. By definition E. Schein (2011), fundamental difference between a leader from a manager is that the former creates the organizational culture, while the second works in it. Perceptions of leadership as a social phenomenon for the first time have been developed in the ideas of the ancient Greek philosophers Pythagoras, Heraclitus, Socrates, Plato, Aristotle. They are mainly linked to the genetic origin of man: leadership an innate property - and only endowed with the gift of this property people have the right to control others. Plato called his greatest talent, and proper training of its use of the right and duty to the constant search for justice, while. Aristotle considered the leader of human courage and self-sacrifice, living for the sake of others. The further development of ideas about leadership is in the ideas of European thinkers. In Hobbes vision leadership is based on the voluntary refusal of people from management and the transfer of powers in exchange for protection of rights and freedoms. In John Locke's rights leaders do not differ from those of others. G.F.V.Gegel noted that leaders create the spirit of the time, and time - leaders. Nietzsche demonstrated most clearly the base of the Great Man theory. They are associated with the attribute of leadership theory, also known as the theory of features that were developed in the nineteenth century. According to this theory, a person becomes a leader due to personal qualities. One of its founders - American explorer Carlisle believed that the basis of a set of heroic leadership qualities. Echoes of this theory are finding a place at the present stage in the form of myth about leader as a superhero. However, attempts to make a list of leadership characteristics have not met with success because it does not guarantee greater effectiveness in their professional activities. One of the first to attempt to understand the cause of leadership Freud, linking leadership with sublimation of the libido in the quest for power and the need for authority with longing for his father. In the theoretical ideas he came out of the negative nature of man, so he takes the lead form of pathology rather than the idea of a professional. Later - in the second half of the twentieth century - they are reflected in the works of Western psychologists. Thus, in particular Adorno and his colleagues (1950) have described the "authoritarian personality." Such a leader alien feelings, imagination and introspection, and he directs the responsibility of the person from outside forces, he stereotyped, rigid thinking, uses power for its own benefit and subject to the authority of others. At the end of the twentieth century, Otto F. Kernberg, M. D. (1998) in the work "Ideology, Conflict, and Leadership in Groups and Organizations", described the pathology leaders (daffodils, schizoid, and others) and gave the characteristics of the processes associated with their behavior in the workplace.

The concept of "leadership" has become widely used in the social sciences after K.Levin experiments (USA, 30th years). He proposed a model for the implementation of changes identified three leadership styles (authoritarian, democratic and anarchist) and proved their direct impact on the "cluster environment» (Lewin, 1951). From this period, the term leadership is firmly embedded in psychological science. In 1943, psychologist K.Craik, continuing the development of ideas about the relationship with the leader of the group, suggested that all events are translated into the internal model, and that people use these models to evaluate external events. This communication theory suggests that people perceive the world through the prism of their psychological perception, and not just the outside world as a whole, despite the fact that they can feel that. Psychologist Philip N. Johnson-Laird has suggested that psychological models form the basis of the basic processes and simple symbols. Theorists generally imply that the groups in which there are 
models work better than the group in which there is no conventional psychological models, such as the pilot commands apply to the take-off and landing (Weick \& Roberts, 1993). Later in 1984 D. Hambrick and P. Mason for the first time suggested that in organizations reflect the views and values of their top managers. This is because the leaders are driven by specific knowledge, experience, values and preferences of the effects on the environment and the creation of such a choice.

Over the last fifty years, psychology has achieved considerable success in matters of motivation. If we take as a key assertion that the whole psychology - social and behavioral aspects, one way or another, are considered in almost every study - the motives are probably the main object of a psychologist, allowing him to explain human behavior, to interpret the actions, to predict the future. According to H.Hekhauzen (2003) "The motive - it is not a concept that describes something, but the concept, designed to explain something." The most interesting in this respect, the study of leadership motives, regarded as perhaps the only way leading to success, and partly understood the psychology of motivation. The largest field to search for the causes of motivation is an integrated approach in B.G.Anan'ev research school, which covers the ontogeny of organic development processes that implement phylogenetic program and individual development is considered in terms of life way. "The life of a man - a history of the formation and development of the individual in a particular society, a contemporary of a certain age and a certain generation peers." (Loginova, 2005) In this approach, a person is considered in its entirety and human life in the natural scale of measurement - from the phase of childhood to maturity phase - Acme, where in the course of individual development work is of great importance.

The behavior of achievements oriented people is described in the studies mainly by American psychologists. It is known that this type of people prefer to solve problems in which the probability of success is $50 \%$. In D.McClelland (2007) "Human Motivation" noted that "... a person with a strong need for achievement should be more activities and avoid routine. They should be more inclined to search for more effective implementation of the tasks. They need to be more creative. The fact that they prefer a moderate degree of difficulty of the problem is that they are constantly looking for a way to pass on what they have done before, to something more difficult. "

In overseas studies have shown that people with a strong motive power have a negative image of the "I", have a problem with alcohol and drugs, men - with sleep, and women with nightmares, experiencing more intense episodes associated with power, tend to be assertive.

In studies of the motives of achievement and highlights the power that their causes may vary in different cultures, and studies of American psychologists characteristics of American culture, in which the person's motivation is related to a person's response to two key questions: "Am I happy?" And "What are my achievements?"

In studies of American psychologists emphasized those remain unsolved issues such as time and circumstances, which can be triggered by certain actions. Russian psychologist E.P.Il'in (2011) noted that the age structure of the motivation is much more complicated, and the foreground is not so much external stimuli as internal - " shift with age motivational determinants in the direction of said internal factors and changes in the ratio between external and internal preferences towards the latter motivator. " Thus, can say that motivation is partly inborn factor is deployed throughout the life course is related to the biographical facts of the individual in the quest for self-discovery, personal fulfillment. However, the causes of a behavior in terms of biographical facts in the psychology of motivation are not considered or in fact there is no answer to the question that led to the result of a person or a decision. Notable examples are shown in the course of life stories of heroes 21st century. The icon of modern youth - Steve Jobs emphasized that he was not loved on the start of life, left his mother and died of pancreatic cancer. However, established his fruit - the bitten apple (a symbol of fertility, new life) is the most socially oriented modern computer, which fully translated his love for other people, in spite of the resistance of reality. Jobs was inventive and introverted. According to the research MBTI among managers alike are both extroverts and introverts. Perhaps there is some connection between the ability to generate ideas, introversion and good governance. However, to the same extent it can be argued that introverts in a different place management processes emotions are more complex mechanisms of perception and information processing - self-regulation. In dealing with such a leader has the illusion of empathic listening. Inability to meet the level of the head - "genius introvert" - turns into an internal disagreement leader - less stable first-person organization to stress, increases feelings of anger, increases the likelihood of developing cancer of the liver or pancreas, which is also enhanced by the adoption of ideas or not the resistance of others.

On the causes of human behavior A. Adler wrote, linking them to the "inferiority complex" and that strength comes from weakness. However, such an explanation in terms of the motivation is not complete. Human behavior towards the goal catalyzed by someone committing acts against it of another person, which causes a reaction and lead to follow, but one way or another for the opening of the phylogenetic program are often manifested in the resistance to the circumstances and conditions in which a person lives. In our culture the cause of people's behavior often comes from a 
position of "they did - because, as we do - even better." Sometimes the reasons for this behavior are dictated by social injustice. In particular, the low level of development of civil society in Russia, greatly increasing the number of people receiving law education. If the weak development of scientific schools and legal nihilism caused by an authoritarian management style, dominant in education, the booming interest in the study of jurisprudence and causing mass entrainment right in the last twenty years associated with violation of human rights. There is reason to believe that the top attainable by man, as determined by the biographical facts. Professor V.A.Bodrov (2006) in his book "Psychological stress: development and overcoming" describes a curious example illustrating achievement motivation - dismissed from the organization people come to other organizations or create their own organizations becoming successful there.

Differences between a person continuously ongoing education from others - the search for truth that is the purpose of scientific research. Often such a way of life - the result of unsuccessful first experience in a sexual relationships or marriage. Together with a high level of ambition this experience provides the need for advances in science, influencing through creativity, dominance, recognition and compensation in love.

The most striking confirmation of the phenomenon of love means work - biographical facts of artists. We know that some of them are born out of wedlock. The most famous example - the genius of Italian art, Leonardo Da Vinci. Famous Russian poet - Athanasius Fet - was also "bastryuk". Such a lack of biographical subsequently leads to its replenishment by means of art, the creation of beauty, despite the social norms and the opinion of the origin of the creator, biographical overcome flaws. From the circumstances to perfection. Not quite Russian roots had a great Russian poet Alexander Pushkin.

Swiss professor F. Malik (2006), said that there is no leadership in national basis (author - in German, Korean or American-style): "Management may be qualitative or wrong, good or bad, but not a national or international, monocultural or multicultural. " Under the influence of national culture on organizational culture should recognize that leadership is a universal phenomenon. In my opinion, in all countries of the world leaders take life as it is, with less distortion vector, are not afraid of pain. A true leader differs from a simple interest in the new. The true motives of leadership - to improve the world. However, they may come up against the resistance and even confusion surrounding. True leaders - it's not only the heroes of large corporations, but also those who work in small organizations (editorial, repair shops, studios, and others). Regardless of the size of the organization they share specifics of communication - they are not arrogant in dealing with a person, regardless of their social status, that is communicating with any person as an equal to them. This is a sure indicator of leadership, motivation to be first.

Despite the fact that many managers become effective with autonomy of human beings, they have no desire for luxury. F. Hertsberg (2007) proved that money is not the key motivator in the work, and the greatest impact on the satisfaction of its five key factors have focused on doing as it pleases, on the success on the recognition on advancing through the ranks as an indication of professional growth. "In recognition of the positive stories usually associated with the successful completion of the execution of a task. In the negative - the lack of recognition of the work reflects the situation under the influence of poor quality or failed policies of administrative action." The leaders of organizations, this motive is expressed to a greater extent - and is linked to their level of self-awareness. True leaders do not value the gold, and simplicity - why in the ability to solve problems through dialogue - it is difficult to find a good companion. Money for leaders means to achieve another goal only, not a goal. In fact, this process can be called motivation for the implementation of the mission or what M.Chiksentmihali (1967) called "flow". For many leaders - their business is the meaning of life. Unfortunately, some leaders are addicted to finding or resort to creating artificial procedures training mission that does not work, because the organizational culture is transmitted from the personal wealth of the founder of the organization. Most leaders have clear moral beliefs, despite the fact that they may be perceived by contemporaries as a strange people. The founder of the Russian aircraft - Zhukovsky when creating the plane caused a lot of ridicule of others - a man with wings on a bicycle. The problems of many modern organizations, just as the absence of moral convictions. In modern world, more vector deviations from a personal mission, biographical facts of their support results in financial losses. This causes the correct behavior and way of life. In more recent studies of motivation (Ricci, Martin, 2009) shows that people with physical motivation prefer to be rewarded for their own efforts, and therefore not effective in teamwork, seeing colleagues as competitors. Put forward as a hypothesis about people with high internal desire for money, combined with the severity of the motive power. They live hard, active life, fraught with the constant risk of losing everything, experiencing the desire for more, causing equally love and hate.

Interesting examples of the effect on the motivation of the biographical facts illustrate examples of biographies of people in education. For example, a famous innovative teacher A.Tubelsky, created the "School of self-determination", the caller is still ambiguous judgment - had a teacher of history education, thesis on working with troubled teenagers, do not fit into the rigid framework of the school, the deputy director of the Palace of creativity. As a result, created an 
educational organization that took in children of parents with different social status and sometimes not fit into the framework of the "traditional school". The spirit of the school resembled a palace of creativity, where there is no single schedule for everyone, but there are general laws adopted by the joint, and the aristocratic spirit inspired the formation of point's leader. One day I was talking with Italian Professor about his life. From his story became clearer history of the formation leader. It illustrates well the relationship of biographical facts, his life and achievements. He was born in Sicily in the south of Italy, educated in Rome, married an Italian who graduated from the University of Bologna, and lived most of his life in the north in the most developed - most of the European part of the country - the center and the top of "boot." End of life came to work in one of the most reputed educational institutions with the name of perhaps the most famous artists - the profile obtained by a professor of education. By the end of his life he led as a leader. H.Hekhauzen, describing people with a strong motivation to achieve, indicates that these people used to leave home, before starting sexual life, often act as a defendant to the letters of other people. They are more active, travel more and more often migrate (Kolp, 1965)

Even before the research conducted F.Hertsberg and D.McCleland, another American psychologist G.Allport (Allport, 1937) emphasized that there are no simple irreducible needs of the individual attributable to all people. "Every individual is unique, as unique and every culture."

The influence of specific education and birth order on the expression of the motives of power and accomplishment is one of fashionable theme. So in one of the Russian studies (Emeliyanenkova A.V. (2001) Psychological and Akmeological features of formation of the motivation power of the executive. Dissertation. Kaluga: The Academy of civil servants) pointed out that the older children in the family show significantly lower results on the avoidance of power, which is more pronounced for older sisters, younger children are more strongly seek power and the same time even more - avoid it. This finding is consistent with data that causes an Italian psychologist A. Menegetti (2007) against alone child. "Only a mother can help her alone child to achieve greatness, because it is difficult to cope with it on their own. Drama of an alone child is that he never takes into account the fact that in life there are others of course, that everything belongs to him, he is inclined to see the world is his. "However, there is a contradiction between the data on the effect of biographies of crystallographic data on the opportunity to take a formal leadership position. For men, the minimum power is characterized by avoidance, if both parents are in leadership positions and the maximum - if the teacher was just the mother. While the H.Hekhauzen the level of achievement of increasingly affected mother. According to these studies, "... the mother of children with severe need for achievement were more authoritarian, gave more specific tips and guidance than the mothers of children with very little need for achievement, while for fathers was characterized by an inverse relationship. Fathers of children with severe need for achievement were significantly less authoritarian than fathers of children with very little need for achievement. In these results, it is important that the dominant behavior of the mother does not preclude the need to achieve and the dominant behavior of the father - on the contrary. " Although the motive to achieve and governments have not relationship, in the context of the management of the organization is likely that successful leaders not only have high levels of motive power and use a variety of means for its application, but also a high level of achievement motive. Only in this case the organization to successfully develop, their leaders pursue them through crises, output to a leading position in its industry. But why biographical combination defines such a result - not always clear, as is the case if both parents of men - heads. What's the real reason? There are no alternative role models - both parents are examples of a future career? Or - the decisive factor is culture? For example, in Asian countries is quite common inheritance of the leadership positions in the dynastic principle, which is also common in collectivist cultures and cultures with a strong division into classes, with a high level of power distance. At the same time, there are many examples, mainly in the western culture, when the leaders who have reached success in business or in the public service, the children do not reach the same position. Devoid of difficulties, secured, ignorant concerns and values of labor often develop complete opposites or ending life drug addiction, suicide. In A.Menegetti (2007) "Project "A man" is an interesting example of the relationship life's journey with the order and the floor child in a family of six children: "The fourth child, a boy (D) - the most unfortunate of all, but sometimes it originally was alone, abandoned by all, can become a genius. In addition, his - his third son - will always love the first-born son (B). Love is in the family of an alternative. "Curious relationship, which I have observed between education of parents and children and life path. We know that many psychologists (as in Russia and abroad) have a basic education as a chemist or a teacher of chemistry and biology (e.g., academic V.S.Muhina). Thus, the subject line of natural science achieved the transition from abstract concepts in chemical science to work, the object of which are people - concrete and tangible, and in the later stages of life as a result of a new field of research achievements. There are examples that prove that scientists and psychologists - children walking along the path of the scientist are becoming specialists in the biological sciences, is particularly pronounced in the male line (father-son). Parents who have received education in both philology, orient the child to education in the 
natural sciences (such as chemistry or boundary areas with medicine). The ratio of education in the field of chemistry and philology sometimes "born" lawyer. Interest in Jurisprudence and the choice of the institution may have a complex nature. Rod mother to the natural sciences, the degree of the father in the life sciences and uncles' interest for human rights leads to the fact that a girl can choose to form the Faculty of Law of the agrarian profile, avoiding conflict denial significant loved ones. That is the nature of individual choice is complex, comprehensive, determining motives and way of life and at the same time associated with multiple influences. Thus, determining the motives of achievement and authority appropriate to take into account the specifics of life. In organizational psychology, influence the leaders of the organization are paramount, and therefore, often state of the organization can be attributed to the head of unconscious perceptions and attitudes toward subordinates. There are cases when the manager prefers to surround themselves with subordinates with lower intelligence or skills, usually by creating an aura of superiority, but in fact only compensating for inferiority. The smart and talented people, sooner or later leave such leaders and such organizations eventually falling into disrepair. They are less susceptible to criticism and assessment of the potential and skills of people. There is reason to believe that the leaders of men, brought up not the second, and the first generation often listened to the advice of elders, or even create organizations that surround him with older age, as this environment is at their comfort zone. That is, the specific way of life determines the order of execution of work, the nature of trust and the balance of the key figures in the organization. In this case - it is the credibility of the more senior in age, which create a protective barrier from the more ambitious young people. It is neither bad nor good. The result is a specific organizational culture. In order norms and values reflected life path of their founders, and decisions, help us to understand what motivates leaders of organizations, make the connection of the life and motivation of leadership. In the natural unfolding development actions, motives are revealed, and the possibilities of interpretation, we can better understand human nature; it is a broader view of the theory of motivation.

Increased in recent years in various areas around the world, the number of women managers suggests overcoming the stereotype of suitability for leadership positions exclusively men. In this connection, the problem of gender differences in human resource management research is one of the leading places. There is a number of approaches to the understanding of differences of male and female controls. In overseas studies, in particular, (Loden, 1985) emphasizes that women managers more concerned to reach agreement, promote the participation of workers in decision-making, to create an atmosphere of openness and develop a sense of ownership value of the subordinates. While men tend more to the competitive spirit, use position in the hierarchy, a strong monitoring and impartially, analytical approach to problem solving. (Rosener, 1990) noted that women leaders are considered more successful transformational-governmental leaders than men, since when the work based more on personality and interpersonal skills. A different view is held by domestic researchers (Krasil'nikova, Pogrebnyak, 2005). According to them, a female leader can sometimes show a more rigid behavior than men who did not feel the margin pressure volitional, and trying not to seem weak men, "overreact" or otherwise - and manipulated in order to smooth out the severity of the conflict or get men to work. A comprehensive approach to the problem taken Sh.M.Burn (2001) in "Social Psychology of Gender ". Based on a meta-analysis, she comes to the conclusion that modern man is desirable to have approximately equal number of male and female traits and their crucial role in the formation of culture and socialization play.

The similarity of the majority of works devoted to gender differences in the management, we concluded in the comparison of men and women together, while virtually no of the works, which were compared to each other representatives of the same sex, not explained the reasons for greater efficiency. For example, on what grounds led by pro-qualification assessment to senior positions in the context of gender differences.

Women tend to be a leader, as a rule, exhibit deviant behavior in childhood. They like to dominate and be the first in group games. In the interview they call games that are traditionally associated with the opposite sex, or have such an experience.

In women with science education and motivation of manipulative trades to power is expressed to a greater extent compared with other professions.

Among managers in education (school principal, dean, Vice-Rector), and in other areas (business owner, artistic director of the theater, and others) are often found women with biographical fact - education of her son by alone. Thus, there is a reason to believe that this biographical fact can be the cause of its suitability to the professional activity of the head. Similar examples are found in the structure of the management teams. As leaders of men and women, there are different types of teams - and heterogeneous and homogeneous. However, men are more likely to prefer heterogeneous management teams. They are balanced, or include both sexes. While women are more likely to prefer same-sex management teams based on strong emotional bonds and the idea of a great complaisance, sense of duty, responsibility and discipline representatives of their sex, or surround themselves with members of the "strong" sex. With resemblance 
structure at the head of the male and female is different motivation. A men - leader in women management teams demonstrates a greater advantage in comparison with members of their own sex that he is the most loved and respected. While a woman leader in the men's team - ambition, power and authority. As a rule, the men in these teams celebrate greater equality and democracy, the lack of unnecessary competition, occurring more often in heterogeneous men's team, which selects the deputy head of the principle of personal devotion, loyalty, and better performance.

\section{References:}

Anan'ev B.G. (2007) Selected works on psychology. St.Peterburg: St.Peterburg University.

Sh.M.Burn (2001) Social Psychology of Gender. St.Peterburg: Euroznuk.

Heckhausen H. (2003) Motivation and action (2nd ed.) Moscow, St.Peterburg: Sense, Piter.

Herzberg F., Mosner B., Sinderman Bloh B. (2007) The motivation to work. Moscow: Acme.

Il'in E.P. (2011) Motivation and motive. St.Peterburg: Piter.

Krasil'nikova K.A., Pogrebnyak T.P. (2005) Gender aspects of management. In Gerasimova L.A. (Ed.), Materials of 2-nd International Conference "Leadership in Gender Perspective" (pp.173-174). St.Peterburg: St.Peterburg University of Information Technologies, Mechanics and Optics.

Loginova N.A. (2005) Experience of anthropology: History of an integrated approach in Bekhterev V.M. and Anan'ev B.G. psychological schools. St.Peterburg: St.Peterburg University.

Malik F. (2006) Managing. Perfoming. Living. Effective Management for a New Era. Frankfurt: Campus Verlag.

McClelland D. (2007) Human Motivation. St.Peterburg: Piter.

Menegetti A. (2007) Project "A man" (2nd ed.) Moscow: Ontopsychology.

Schein E. (2011) Organizational Culture and Leadership. (3rd ed.). St.Peterburg: Piter. 